\title{
A multi-center study on the attitudes of Malaysian emergency health care staff towards allowing family presence during resuscitation of adult patients
}

\author{
Chew Keng Sheng • Chee Kean Lim • Ahmad Rashidi
}

Received: 18 November 2009 /Accepted: 1 July 2010 /Published online: 21 August 2010

(C) Springer-Verlag London Ltd 2010

\begin{abstract}
s
Background The practice of allowing family members to witness on-going active resuscitation has been gaining ground in many developed countries since it was first introduced in the early 1990s. In many Asian countries, the acceptability of this practice has not been well studied.

Aim We conducted a multi-center questionnaire study to determine the attitudes of health care professionals in Malaysia towards family presence to witness ongoing medical procedures during resuscitation.

Methods Using a bilingual questionnaire (in Malay and English language), we asked our respondents about their attitudes towards allowing family presence (FP) as well as their actual experience of requests from families to be allowed to witness resuscitations. Multiple logistic regression was used to analyze the association between the many variables and a positive attitude towards FP.

Results Out of 300 health care professionals who received forms, 270 responded (a 90\% response rate). Generally only $15.8 \%$ of our respondents agreed to allow relatives to witness resuscitations, although more than twice the number $(38.5 \%)$ agreed that relatives do have a right to be around during resuscitation. Health care providers are significantly more likely to allow FP if the procedures are perceived as likely to be successful (e.g., intravenous cannulation and blood taking as compared to chest tube
\end{abstract}

The views expressed in this paper are those of the author(s) and not those of the editors, editorial board or publisher.

C. K. Sheng $(\bowtie) \cdot$ C. K. Lim · A. Rashidi

Emergency Medicine Department, School of Medical Sciences, Universiti Sains Malaysia,

16150, Kubang Kerian,

Kelantan, Malaysia

e-mail: cksheng74@yahoo.com

e-mail: cksheng74@kb.usm.my insertion). Doctors were more than twice as likely as paramedics to agree to FP ( $\mathrm{p}$-value $=0.002$ ). This is probably due to the Malaysian work culture in our health care systems in which paramedics usually adopt a 'followthe-leader' attitude in their daily practice.

Conclusion The concept of allowing FP is not well accepted among our Malaysian health care providers.

Keywords Family presence - Witnessed resuscitation . Malaysian community

\section{Introduction}

Over the last century, technological and pharmaceutical advancement has spurred the health care profession to move beyond the scope of caring for the living to prolonging the dying process. Although the paternalistic, "top-down" paradigm, adopted from the Western concept of caring for the ill, has been in place for the past several decades [1], this concept, by and large, is incongruent with Asian culture in which a patient is foremost an individual of the community, and in dying, he or she returns to the community. Asian elderly usually die in the arms of their family and not in a cold, sterile room in an intensive care unit, a chaotic emergency department or a crowded ward.

Humanizing cardiopulmonary resuscitation (CPR) and affording peace, comfort and dignity during the dying process should therefore be a prime consideration during resuscitation [2]. The concept of witnessed resuscitation, which means allowing the presence of family members or relatives during the process of active resuscitation, has been gaining ground in the United States since it was first introduced in 1987 at Foote Hospital in Michigan [1, 3]. This concept then spread to other hospitals and has found 
strong advocates, especially among those involved in the resuscitation of pediatric patients $[1,4,5]$.

Nonetheless, concepts like allowing family members to witness the process of resuscitation as well as other medical procedures have not been extensively studied in Asian populations. Ong et al., who studied the attitudes of medical staff at Singapore General Hospital towards witnessed resuscitation by family members, found that $80 \%$ of doctors and $78 \%$ of nurses said no to allowing family members to witness the process of resuscitation [6]. The reasons cited for not favoring witnessed resuscitation include concern that the experience will be traumatic for the family, that family members could ask too many questions and thereby interfere with the procedures, that family members impose additional stress on the staff performing the resuscitation and that medicolegal issues might arise [6]. A further study carried out at a later time to compare the attitudes of the public and medical staff towards witnessed resuscitation in Singapore found a great discrepancy between these two groups [7]. In that study, up to $73.1 \%$ of the public supported witnessed resuscitation; however, only $10.6 \%$ of the medical staff surveyed at Singapore General Hospital wanted to allow witnessed resuscitation [7].

Malaysia has a population of over 28.31 million people [8]: $50.4 \%$ are Malay, $11.0 \%$ indigenous groups from Sabah and Sarawak, 23.7\% Chinese, and 7.1\% Indians and others [9]. We conducted a multi-center, prospective questionnaire study to determine the general attitudes of health care professionals (HCPs) in Malaysia towards family presence (FP) to witness ongoing medical procedures during resuscitation.

\section{Methods}

This study was conducted from 1 June 2008 to 31 December 2008 in four locations: Hospital Kuala Lumpur (HKL), Hospital Pulau Pinang (HPP), Hospital Universiti Sains Malaysia (HUSM) and Universiti Malaya Medical Centre (UMMC). HKL is the largest hospital in Malaysia under the Ministry of Health Malaysia (MOH) and is considered to be one of the biggest in Asia [10, 11]. It is a government tertiary referral hospital, located on 150 acres of prime land, and has 83 wards and 2,302 beds [10]. HPP is the second largest MOH with 1,090 beds [12]. The MOHs are generally considered as service government hospitals in Malaysia and cater to a large volume of patients.

HUSM is a teaching hospital under the Ministry of Higher Education with 723 beds [13]. UMMC is another teaching hospital located in the Selangor state, with a total of 900 beds [14].

The self-administered bilingual questionnaire (in Malay and English language) is divided into three sections: demographic data, the attitudes of staff towards allowing family presence and the actual experience of staff with family requests to be allowed to witness the resuscitation. All personnel in emergency departments who are directly involved in the clinical care of patients in emergency departments (i.e., doctors, paramedics and health attendants) of the four hospitals mentioned were included, whereas personnel who are not directly involved in the care of patients, such as the radiological staff, laboratory technicians and cleaning staff, were excluded.

We handed out a total of 300 questionnaire forms in envelopes to the participants. After completing the forms, the participants were instructed to insert the forms back into the envelopes provided. We told them that we would collect the forms 2 days later. The participants were also reminded not to add their names as the survey was anonymous.

Data entry and analysis were done using Statistical Package for Social Studies (SPSS ${ }^{\circledR}$ ) version 16.0 software. Univariate analysis was done for categorical data using simple logistic regression (SLR) with a p-value $<0.05$ considered statistically significant. Multivariate analysis using multiple logistic regression (MLR) was subsequently performed to reduce potential cofounders in our effort to analyse variables that favor family presence during resuscitation. Ethical approval was obtained from the various institutional research ethics boards of the hospitals concerned.

\section{Results}

A total of 300 forms were distributed, and 270 health care professionals responded (a response rate of 90\%). Generally, only $15.8 \%$ of our respondents agreed to allow relatives to witness resuscitation, although more than twice that number (38.5\%) agreed that relatives do have a right to be around during resuscitation.

The results of our descriptive analysis are shown in Table 1. The attitudes of HCPs towards FP are shown in Table 2, whereas Table 3 shows the results of the past experiences of HCPs towards dealing with relatives of patients, especially with regards to allowing FP during resuscitation.

Several variables were later re-coded into binary options, and using multiple logistic regressions to analyze the association between the acceptance of FP and various factors, we found that the type of occupation (doctors versus paramedics) has statistically significant influence on the acceptance of FP. Compared to paramedics, the adjusted odds of doctors agreeing to allowing family presence during resuscitation were 2.86 times more likely ( $\mathrm{p}$-value $=0.002)$. 
Table 1 Results of descriptive analysis of respondents

\begin{tabular}{|c|c|c|}
\hline Variable & Mean (SD) & Frequency $(\%)$ \\
\hline Age (years) & $31.57(7.33)$ & \\
\hline \multicolumn{3}{|l|}{ Sex } \\
\hline Male & & $134(49.6)$ \\
\hline Female & & $133(49.3)$ \\
\hline Not-specified & & $3(1.1)$ \\
\hline \multicolumn{3}{|l|}{ Race } \\
\hline Malay & & $213(78.90)$ \\
\hline Chinese & & $16(5.9)$ \\
\hline Indian & & $30(11.1)$ \\
\hline Others & & $11(4.1)$ \\
\hline \multicolumn{3}{|l|}{ Religion } \\
\hline Muslim & & $218(80.8)$ \\
\hline Buddhist & & $12(4.4)$ \\
\hline Hindu & & $24(8.9)$ \\
\hline Christian & & $10(3.7)$ \\
\hline Others & & $6(2.2)$ \\
\hline \multicolumn{3}{|c|}{ Workplace: emergency department in } \\
\hline HUSM & & $64(23.7)$ \\
\hline UMMC & & $46(17.0)$ \\
\hline HKL & & $83(30.7)$ \\
\hline HPP & & $77(28.5)$ \\
\hline \multicolumn{3}{|l|}{ Job description } \\
\hline Emergency physician & & $2(0.7)$ \\
\hline Medical officer & & $87(32.2)$ \\
\hline Staff nurse & & $101(37.4)$ \\
\hline Medical assistant & & $64(23.7)$ \\
\hline Unspecified & & $16(6.0)$ \\
\hline
\end{tabular}

\section{Discussion}

Allowing FP during resuscitation has many benefits. The benefits include ensuring continuing patient-family bonding and connectedness [15], facilitating the grief process [16], promoting a sense of closeness around a life shared together [17], assuring family members that everything possible has been done [5], allowing space for spiritual rituals and activities [15], conveying a message that the HCPs have been supportive and helpful to the patient [18], and helping to reduce fear and anxiety [19].

Nevertheless, while the concept of witnessed resuscitation is becoming popular in Western countries, it is practically unheard of in our Asian society [20]. It would seem, therefore, that Asian medical staff may have a greater resistance to allowing FP than their Western counterparts $[6,21]$.

In our study, we found that about $40.0 \%$ of HCPs would allow FP during IV cannulation and blood taking as compared to more invasive procedures. For example, for chest tube insertion, only $2.9 \%$ would say that they agree to
Table 2 Attitudes of HCPs towards FP

\begin{tabular}{ccc}
\hline & $\begin{array}{l}\text { Frequency } \\
(\mathrm{n}), \text { total }\end{array}$ & $\begin{array}{c}\text { Percentage } \\
(\%)\end{array}$ \\
$\mathrm{n}=270$ & \\
\hline
\end{tabular}

Would you allow relatives to witness resuscitation?

$\begin{array}{lll}\text { Yes } & 43 & 15.8 \\ \text { No } & 227 & 83.2\end{array}$

Do relatives have a right to be present during resuscitation?

$\begin{array}{lll}\text { Yes } & 105 & 38.9 \\ \text { No } & 161 & 59.6 \\ \text { Don't know } & 4 & 1.5 \\ \text { hen should relatives be present? } & & \\ \text { Never } & 66 & 24.4 \\ \text { After all invasive procedures } & 195 & 72.2 \\ \text { During the whole resuscitation } & 8 & 3.0 \\ \text { Missing data } & 1 & 0.4\end{array}$

Would you allow relatives to witness the following invasive procedures?

$\begin{array}{lll}\text { IV line } & 110 & 40.7 \\ \text { Blood taking } & 112 & 41.5 \\ \text { Intubation } & 12 & 4.4 \\ \text { Foley catheter } & 11 & 4.1 \\ \text { CVL insertion } & 18 & 6.7 \\ \text { Chest tube insertion } & 8 & 3.0 \\ \text { Rectal examination } & 14 & 5.2 \\ \text { Close manual reduction of fracture } & 33 & 12.2 \\ \text { CPR } & 48 & 17.8\end{array}$

Agree that the following are reasons you are against allowing FP

$\begin{array}{lll}\text { Traumatic experience } & 207 & 76.7 \\ \text { Medico-legal issues } & 184 & 68.1 \\ \text { Breach of privacy } & 152 & 56.3 \\ \begin{array}{l}\text { FP interferes with resuscitative } \\ \text { process }\end{array} & 225 & 83.3 \\ \text { Overcrowding } & 174 & 64.4 \\ \text { Stress to staff } & 204 & 75.6 \\ \text { Prolonging futile resuscitation } & 84 & 31.1 \\ \text { al no. of relatives during resuscitation } & & \\ \text { None } & 140 & 51.9 \\ 1 & 100 & 37.0 \\ 2-3 & 30 & 11.1\end{array}$

Who should make the decision to allow FP?

$\begin{array}{lll}\text { Senior doctor } & 118 & 43.7 \\ \text { Nursing officer } & 2 & 0.7 \\ \text { Team decision } & 62 & 23.0 \\ \text { Department policy } & 85 & 31.5 \\ \text { Don't know } & 3 & 1.1\end{array}$

Should HCPs provide emotional support during FP?

$\begin{array}{lll}\text { Yes } & 228 & 84.4 \\ \text { No } & 35 & 13.0 \\ \text { Missing data } & 7 & 2.6\end{array}$

You agree that the following are advantages of FP

Assuring everything has been done $\quad 192 \quad 71.1$ 
Table 2 (continued)

\begin{tabular}{|c|c|c|}
\hline & $\begin{array}{l}\text { Frequency } \\
(\mathrm{n}), \text { total } \\
\mathrm{n}=270\end{array}$ & $\begin{array}{l}\text { Percentage } \\
(\%)\end{array}$ \\
\hline Aids grieving & 64 & 23.7 \\
\hline Strengthen bond & 31 & 11.5 \\
\hline Enable last rites & 172 & 63.7 \\
\hline \multicolumn{3}{|c|}{$\begin{array}{l}\text { You agree that the following family members would benefit from } \\
\text { witnessing resuscitation }\end{array}$} \\
\hline Parents of a pediatric patient & 230 & 85.2 \\
\hline Spouses of patient & 197 & 73.0 \\
\hline Siblings of pediatric cases & 31 & 11.5 \\
\hline Offspring of geriatric patients & 146 & 54.1 \\
\hline \multicolumn{3}{|c|}{$\begin{array}{l}\text { You agree that the following categories of patients would benefit from } \\
\text { FP }\end{array}$} \\
\hline Patients with acute illnesses & 103 & 38.2 \\
\hline Patients with chronic illnesses & 110 & 40.7 \\
\hline Trauma patients & 97 & 35.9 \\
\hline Patients with terminal illnesses & 129 & 47.8 \\
\hline \multicolumn{3}{|c|}{ Will you be uncomfortable with FP? } \\
\hline Yes & 229 & 84.8 \\
\hline No & 39 & 14.4 \\
\hline Missing data & 2 & 0.8 \\
\hline \multicolumn{3}{|l|}{$\begin{array}{l}\text { Will you be more willing to allow } \\
\text { FP if the relatives are medical } \\
\text { staff? }\end{array}$} \\
\hline Yes & 164 & 60.7 \\
\hline No & 103 & 38.2 \\
\hline Missing data & 3 & 1.1 \\
\hline
\end{tabular}

allow FP (see Table 2). Furthermore, it seems that HCPs are more likely to allow FP during procedures if the procedures are likely to be successful [22]. IV cannulation and blood taking are routine procedures performed even in nonemergent conditions. Procedures that involved exposing the patients' private parts were also less likely to be agreed to by HCPs for FP (e.g., only $4.0 \%$ agreed to FP during Foley catheterization and for rectal examination, 5.1\%). This may be explained by the ethical principles upheld by HCPs to protect patients' privacy.

Surprisingly, however, we found that many HCPs (17.6\%) agreed to allow FPs during CPR (see Table 2). This may be due to the fact that many HCPs realize that resuscitation moments may be the last chance for a family member to bid farewell to their dying loved ones. This is consistent with another finding in our study that $63.0 \%$ of HCPs agree that FP would enable the family members to perform last rites. This is because one aspect of dying in Islam is the pronouncement of the 'shahadah' to the neardying patient. For Roman Catholics, there is also the giving of last rites during such moments.
Table 3 The past experiences and attitudes of HCPs when dealing with relatives of patients

\begin{tabular}{|c|c|c|}
\hline & $\begin{array}{l}\text { Frequency } \\
\mathrm{n}\end{array}$ & $\begin{array}{l}\text { Percentage, } \\
\%\end{array}$ \\
\hline \multicolumn{3}{|c|}{ Previous requests from relatives for FP } \\
\hline Yes & 194 & 71.1 \\
\hline No & 76 & 27.8 \\
\hline \multicolumn{3}{|c|}{$\begin{array}{l}\text { Number of requests for FP in last } 6 \\
\text { months }\end{array}$} \\
\hline No & 98 & 35.9 \\
\hline $1-5$ & 112 & 41.0 \\
\hline $6-10$ & 24 & 8.8 \\
\hline$>10$ & 30 & 11.0 \\
\hline Missing data & 6 & \\
\hline \multicolumn{3}{|c|}{ Your first reaction when asked for FP } \\
\hline Anxious & 66 & 24.4 \\
\hline Dilemma & 121 & 44.8 \\
\hline Frustration & 6 & 2.2 \\
\hline Can't remember & 77 & 28.6 \\
\hline \multicolumn{3}{|c|}{ Will you take the initiative to explain about resuscitation to relatives? } \\
\hline Yes & 230 & 85.2 \\
\hline No & 34 & 12.6 \\
\hline Don’t know & 6 & 2.2 \\
\hline \multicolumn{3}{|c|}{ Relative's reaction to resuscitation? } \\
\hline Shock & 112 & 41.5 \\
\hline Disgusted & 11 & 4.1 \\
\hline Accepting & 112 & 41.5 \\
\hline Indifferent & 9 & 3.3 \\
\hline Not sure & 26 & 9.6 \\
\hline
\end{tabular}

As mentioned earlier, using multiple logistic regression, we found that doctors were more than twice as likely as paramedics to agree to FP ( $\mathrm{p}$-value $=0.002$ ). This is probably due to the work culture in our health care system. This finding is consistent with another finding that $43.2 \%$ of respondents felt that the decision to allow FP should be made by a doctor compared to $22.7 \%$ who think that it is a team policy. In Malaysia, in the absence of a departmental policy or guideline, paramedics will usually adopt a 'follow-the-leader' attitude in their daily practice. Therefore, even if they do feel that family members have a right, they would be less likely to make the decision to allow FP, preferring to leave it to a senior doctor to make the decision (see Table 2).

On the other hand, doctors are usually the decision maker in areas where no institutional policies are implemented. They are more likely to make the decision to allow FP.

Our study has several limitations. The respondents in this study were HCPs working in busy emergency departments, and therefore some of them did not complete the survey forms. As the study was a voluntary, anonymous 
survey, it is possible that respondents who did not favor family presence were less likely to participate in the study. Furthermore, as we allowed the respondents to fill in the questionnaire anonymously, this may allow potential information bias because of over or under reporting. And finally, as the study was confined to four hospitals, this may not be reflective of the true HCP population in Malaysia.

\section{Conclusion}

In conclusion, our study found that the concept of allowing FP is not well accepted among our Malaysian HCPs (only $15.8 \%$ would agree to allow FP). One of the potential future studies that we hope to conduct would involve trying to understand the perception of FP from the other end of the rope - that of the Malaysian general public.

Acknowledgment The authors wish to express our sincere appreciation to Associate Professor Dr. Marcus Ong Eng Hock of Singapore General Hospital for graciously allowing us to adapt his questionnaire in formulating our survey form solely for the purpose of this study.

Conflict of Interest None

\section{References}

1. Boudreaux ED, Francis JL, Loyacano T (2002) Family presence during invasive procedures and resuscitations in the emergency department: a critical review and suggestions for future research. Ann Emerg Med 40(2):193-205

2. Mazer MA, Cox LA, Capon JA (2006) The public's attitude and perception concerning witnessed cardiopulmonary resuscitation. Crit Care Med 34(12):2925-2928

3. Boyd R (2000) Witnessed resuscitation by relatives. Resuscitation 43(3):171-176

4. Mangurten J, Scott SH, Guzzetta CE et al (2006) Effects of family presence during resuscitation and invasive procedures in a pediatric emergency department. J Emerg Nurs 32(3):225-233

5. Bauchner H, Waring C, Vinci R (1991) Parental presence during procedures in an emergency room: results from 50 observations. Pediatrics 87(4):544-548

6. Ong ME, Chan YH, Srither DE, Lim YH (2004) Asian medical staff attitudes towards witnessed resuscitation. Resuscitation 60(1):45-50

7. Ong ME, Chung WL, Mei JS (2007) Comparing attitudes of the public and medical staff towards witnessed resuscitation in an Asian population. Resuscitation 73(1):103-108

8. Population (Updated: 31/07/2009) In: Department of Statistics Malaysia Official Website. Available at: http://bit.ly/3CU8hb Accessed 15 Nov 2009
9. Malaysia. In: Wikipedia. Available at: http://en.wikipedia.org/ wiki/Malaysia. Accessed 15 Nov 2009

10. Our Profile. Hospital Kuala Lumpur In: Hospital Kuala Lumpur webpage. Available at: http://www.hkl.gov.my/. Accessed 16 Nov 2009

11. Kuala Lumpur General Hospital. In: Wikipedia. Available at: http://en.wikipedia.org/wiki/Kuala_Lumpur_General_Hospital. Accessed 14 Nov 2009

12. Pengenalan Hospital Pulau Pinang In: Hospital Pulau Pinang webpage. Available at: http://hpp.moh.gov.my/modules/xt conteudo/index.php?id=143. Accessed 14 Nov 2009

13. Hospital Universiti Sains Malaysia. In: School of Medical Sciences, Universiti Sains Malaysia website. Available at http:// www.medic.usm.my/welcome/?page=facilities. Accessed 14 Nov 2009

14. University Malaya Medical Centre. In: Wikipedia. Available at: http://en.wikipedia.org/wiki/University_Malaya_Medical_Centre. Accessed 14 Nov 2009

15. Meyers TA, Eichhorn DJ, Guzzetta CE, Clark AP, Klein JD, Taliaferro E, Calvin A (2000) Family presence during invasive procedures and resuscitation. Am J Nurs 100(2):32-42

16. Doyle CJ, Post H, Burney RE, Maino J, Keefe M, Rhee KJ (1987) Family participation during resuscitation: an option. Ann Emerg Med 16(6):673-675

17. Hanson C, Strawser D (1992) Family presence during cardiopulmonary resuscitation: Foote Hospital emergency department's 9year perspective. J Emerg Nurs 18(2):104-106

18. Sacchetti A, Lichenstein R, Carraccio CA, Harris RH (1996) Family member presence during pediatric emergency department procedures. Pediatr Emerg Care 12(4):268-271

19. Shapira M, Tamir A (1996) Presence of family member during upper endoscopy. What do patients and escorts think? J Clin Gastroenterol 22(4):272-274

20. Muller JH, Desmond B (1992) Ethical dilemmas in a crosscultural context. A Chinese example. West J Med 157(3):323-327

21. Zakaria M, Siddique M (2008) Presence of family members during cardio-pulmonary resuscitation after necessary amendments. J Pak Med Assoc 58(11):632-635

22. Sacchetti A, Guzetta CE, Harris RH (2003) Family presence during resuscitation attempts and procedures: is there science behind the emotion? Clin Pediatr Emerg Med 4:292-296

Dr. Chew Keng Sheng MD, MMed, is an emergency physician and senior lecturer in emergency medicine at Universiti Sains Malaysia. His special interests include cardiopulmonary resuscitation, critical care interventions and medical education in emergency medicine.

Dr. Lim Chee Kean MD, MMed, is an emergency physician working with the Ministry of Health of Malaysia. Her special interest is in cardiopulmonary resuscitation and ethical issues in resuscitation.

Dr. Rashidi Ahmad MD, MMed, is an emergency physician and associate professor in emergency medicine at Universiti Sains Malaysia. His special interests include emergency coronary care, cardiopulmonary resuscitation and medical education in emergency medicine. 